\title{
Compensation for the influence of temperature and humidity on oxygen diffusion in a reactive polymer matrix
}

\author{
P. Marek ${ }^{1}$, J. J. Velasco-Veléz ${ }^{2}$, T. Doll ${ }^{3}$, and G. Sadowski ${ }^{1}$ \\ ${ }^{1}$ TU Dortmund, Laboratory of Thermodynamics, Emil-Figge-Str. 70, 44227 Dortmund, Germany \\ ${ }^{2}$ University of California, Berkeley, Department of Material Science and Engineering, Berkeley, \\ CA 94720, USA \\ ${ }^{3}$ BioMaterial Engineering, HNO, Hannover Medical School, Feodor-Lynen Str. 35, Hannover, Germany \\ Correspondence to: G. Sadowski (gabriele.sadowski@bci.tu-dortmund.de)
}

Received: 21 April 2014 - Revised: 10 October 2014 - Accepted: 28 October 2014 - Published: 17 November 2014

\begin{abstract}
In a previous work (Marek et al., 2013) a time-monitoring oxygen sensor was proposed. This sensor is based on a diffusion-controlled oxygen reaction of the indicator system methylene blue (MB)/leuco methylene blue (LMB) and riboflavin embedded in a water-loaded poly(vinyl alcohol) (PVA) matrix. It can be used in packaging, sensors, and biotechnology applications. Since the oxygen diffusion coefficient in the PVA matrix strongly depends on temperature and humidity, two different approaches were developed within this work to compensate for these two effects. To compensate for faster oxygen diffusion at higher temperatures, iron particles were added to the PVA matrix, resulting in a novel PVA/iron composite matrix. Adding silicone particles allows compensating the influence of humidity. Both temperature and humidity compensation were modeled using the finite-element method in good accordance with the experimental data. This allows tuning the sensor for application at different conditions of temperature and humidity and therewith in different environments.
\end{abstract}

\section{Introduction}

Oxygen, although essential for life, often causes the spoilage of food, medicines, cosmetics, and even electronics (Rooney, 1995). It allows for the growth of microorganisms and a variety of chemical oxidation reactions in these products, which are usually associated with negative consequences. To avoid the damage caused by oxygen, most consumer goods are packaged under a modified atmosphere (MAP) (Mills, 2005). During this process, the oxygen content is reduced by flushing the package volume with an inert gas (Phillips, 1996). Although the MAP technology prolongs the shelf life of many products, the spoilage of consumer goods cannot be avoided using this packaging technology because the oxygen might enter the packaging material via permeation (Rooney, 1995). However, the use of high-barrier packaging materials can decrease the oxygen transfer rate (OTR). An example for such a high-barrier material is poly(vinyl alcohol) (PVA) (Lange and Wyser, 2003; Mokwena and Tang, 2012). It is also a very good material for the immobilization of drugs, chemicals, indicators, enzymes, and cells (Pritchard, 1970; Finch, 1973). Also for these applications, oxygen diffusion plays a crucial role. However, this material is not established in the packaging industry because of its partially unknown permeation properties for oxygen. Moreover, the permeation and diffusion of oxygen into polymers are mainly determined by their water content (directly related to relative humidity RH; Jack et al., 2011) and by temperature. For numerous applications, such as for time monitoring (Marek et al., 2013) based on oxygen diffusion, this leads to incorrect outcomes as e.g., oxygen diffusion is increased with increasing temperature and water content.

To maintain an oxygen-free atmosphere, oxygen scavengers which consume oxygen were developed (Rooney, 1995; Wanner, 2010) and integrated in different materials. Most of the scavengers that have been incorporated into polymer films are chemical substances, such as $\mathrm{Na}_{2} \mathrm{SO}_{3}$, ascorbic acid (Rooney, 1995), or metals such as iron, aluminum, and 
copper (Wanner, 2010). However, so far, oxygen scavengers were only applied to consume a maximum amount of oxygen over the longest possible time but control of oxygen permeability using scavengers has not been examined yet.

In this work new compensation approaches have been developed and applied to compensate for the effect of temperature and humidity on oxygen diffusion in oxygen sensors (e.g., Marek et al., 2013). For their applications such as in the packaging or sensor technology, this dependency is undesirable. Faster oxygen diffusion due to higher temperature can be compensated using oxygen scavengers integrated into the sensor matrix (PVA matrix). At higher temperatures, more oxygen is consumed by the scavenger reaction with diffusing oxygen. The humidity compensation can be realized by replacing part of the PVA in the PVA matrix with nonwater absorbing elements such as silicone particles, as in these elements the oxygen diffusion stays humidity-independent.

\section{Experiments}

\subsection{Materials}

Methylene blue (MB) was obtained from Merck KGaA (Darmstadt, Germany), and PVA (Mowiol 98) from Kuraray Europe GmbH (Frankfurt am Main, Germany). According to the manufacturer, the PVA had a degree of hydrolysis of $98.4 \%$ (per mole) and a molar mass of $47000 \mathrm{~g} \mathrm{~mol}^{-1}$. Riboflavin was obtained from BDH Prolabo. The iron particles $(10 \mu \mathrm{m})$ were obtained from Merck KGaA and were stored in a vacuum to avoid oxidation. Sodium chloride $(\mathrm{NaCl})$ was also obtained from Merck KGaA. The Dow Corning EP-9215 silicone particles were a cosmetic powder $(5 \mu \mathrm{m})$ and had a specific volume of $0.00102 \mathrm{~m}^{3} \mathrm{~kg}^{-1}$. All materials were used as obtained without further purification.

\subsection{Preparation of the PVA composite matrices}

An aqueous indicator solution consisting of $\mathrm{MB}$ and riboflavin was prepared. The MB concentration in the indicator solution varied between $7.8 \times 10^{-8} \mathrm{~mol} \mathrm{~m}^{-3}\left(0.025 \mathrm{~g} \mathrm{~L}^{-1}\right)$ and $3.12 \times 10^{-7} \mathrm{~mol} \mathrm{~m}^{-3}\left(0.1 \mathrm{~g} \mathrm{~L}^{-1}\right)$ and the riboflavin concentration varied between $1.0 \times 10^{-8} \mathrm{~mol} \mathrm{~m}^{-3}\left(0.004 \mathrm{~g} \mathrm{~L}^{-1}\right)$ and $2.6 \times 10^{-8} \mathrm{~mol} \mathrm{~m}^{-3}\left(0.01 \mathrm{~g} \mathrm{~L}^{-1}\right)$. After that, PVA of mass fractions between 0.2 and 0.4 was completely dissolved in these solutions for approximately $2 \mathrm{~h}$ at $80^{\circ} \mathrm{C}$.

For temperature-compensation experiments, iron particles as well as $\mathrm{NaCl}$ were added to these PVA solutions. The final iron mass fraction in the PVA composite matrix varied between 0.01 and 0.06 , the final $\mathrm{NaCl}$ mass fraction in PVA composite matrix was always below 0.02 . For humiditycompensation experiments, silicone particles were added to the above-mentioned PVA solutions. The silicone mass fraction in the final PVA composite matrix was up to 0.25 . For the measurement of water sorption in the PVA/ $\mathrm{NaCl}$ matrix,
$\mathrm{NaCl}$ was directly added to PVA solutions (in the absence of $\mathrm{MB}$ and riboflavin).

The resulting mixtures were placed on a glass surface and subsequently flattened using a drawdown rod with a slit of a defined height between 450 and $850 \mu \mathrm{m}$. After approximately $12 \mathrm{~h}$, the polymer films were removed from the glass plate, cut, and transferred into a climate test chamber (WKL 34/40, Weiss Umwelttechnik GmbH, Reiskirchen, Germany). Temperature and RH in the chamber were set and measured using a Vaisala HUMICAP ${ }^{\circledR}$ Humidity and Temperature Transmitter Series HMT310 instrument with an accuracy of $\pm 1.0 \%$ for RHs between 0 and 90 and $\pm 1.7 \%$ for RHs over $90 \%$ at $20{ }^{\circ} \mathrm{C}$ (temperature accuracy $\pm 1.0 \%$ ), respectively.

To achieve the desired water mass fraction in the final PVA films, they were equilibrated at RH and temperature of interest (see Table 1) for at least $24 \mathrm{~h}$. The correlation between the water mass fraction in PVA on the one hand and RH and temperature in the surrounding atmosphere on the other hand was already described in Jack et al. (2011) and Marek et al. (2013). The temperatures, RH and resulting water mass fractions in the investigated PVA films are summarized in Table 1 .

Depending on the water content in the PVA matrix, the final MB concentration in the PVA matrix varied between $0.31 \mathrm{~mol} \mathrm{~m}^{-3}$ in experiments for determination of oxygen diffusion coefficients and $0.36 \mathrm{~mol} \mathrm{~m}^{-3}$ for temperature- and humidity-compensation experiments. The final riboflavin concentration in the PVA matrix was about $0.05 \mathrm{~mol} \mathrm{~m}^{-3}$ in all cases. These MB and riboflavin concentrations refer to the final volume of the equilibrated water-loaded PVA matrix which was determined using the densities also given in Table 1. The latter were calculated applying the equation of state PC-SAFT (rerturbed-chain statistical associating fluid theory; Gross and Sadowski, 2002) using the parameters given in the Appendix A1.

The thickness of the polymer films was determined using a QNix 1200 (Automation Dr. Nix GmbH \& Co. KG) coatingthickness measuring instrument. The experiments were performed with films of $170 \pm 5$ or $180 \pm 5 \mu$ m thicknesses.

To remove the oxygen from the PVA composite matrix before the experiments (see activation of the films in Marek et al., 2013), the films were finally irradiated by UV (ultraviolet) light using an Osram Ultra-Vitalux $300 \mathrm{~W}$ lamp under a nitrogen atmosphere until the films turned yellow. After the activation the yellow-colored films contain no oxygen as already shown in Marek et al. (2013).

\subsection{Measurements of water sorption in the PVA/NaCl composite matrix}

Water sorption measurements of $\mathrm{PVA} / \mathrm{NaCl}$ films were performed by measuring the water mass fraction in the $\mathrm{PVA} / \mathrm{NaCl}$ films at a certain temperature and humidity. First, the PVA/NaCl films were equilibrated at a defined $\mathrm{RH}$ and temperature in the above-mentioned WKL 34/40 climate test 
Table 1. Correlation between the temperature, RH and water mass fraction in the PVA matrix for conditions investigated in this work. The density as well as oxygen solubility of the resulting water-loaded PVA films at these conditions are also given.

\begin{tabular}{rrrrr}
\hline $\begin{array}{r}\text { Temperature } \\
(\mathrm{K})\end{array}$ & $\begin{array}{r}\text { RH } \\
(\%)\end{array}$ & $\begin{array}{r}\text { Water mass } \\
\text { fraction in PVA } \\
\text { matrix }\left(\mathrm{g} \mathrm{g}^{-1}\right)\end{array}$ & $\begin{array}{r}\text { Density of } \\
\text { water-loaded PVA } \\
\text { matrix }\left(\mathrm{kg} \mathrm{m}^{-3}\right)\end{array}$ & $\begin{array}{r}\text { Oxygen concentration } \\
\text { in PVA matrix } \\
\left(\mathrm{mol} \mathrm{m}^{-3}\right)^{*}\end{array}$ \\
\hline 298.15 & 90 & 0.170 & 1230 & 0.045 \\
303.15 & 90 & 0.170 & 1226 & 0.041 \\
308.15 & 90 & 0.170 & 1221 & 0.038 \\
313.15 & 90 & 0.170 & 1216 & 0.035 \\
293.15 & 85 & 0.133 & 1248 & 0.039 \\
298.15 & 85 & 0.133 & 1243 & 0.035 \\
308.15 & 85 & 0.133 & 1233 & 0.030 \\
313.15 & 85 & 0.133 & 1228 & 0.027 \\
298.15 & 80 & 0.110 & 1250 & 0.029 \\
303.15 & 80 & 0.110 & 1245 & 0.026 \\
313.15 & 80 & 0.110 & 1235 & 0.023 \\
298.15 & 75 & 0.089 & 1258 & 0.024 \\
303.15 & 75 & 0.089 & 1252 & 0.021 \\
313.15 & 75 & 0.089 & 1242 & 0.019 \\
298.15 & 70 & 0.073 & 1263 & 0.019 \\
\hline
\end{tabular}

* Obtained from Marek et al. (2013).

chamber. The films were repeatedly weighed with an accuracy of $\pm 0.1 \mathrm{mg}$ until the mass of the samples remained constant. After that, the films were dried at $120^{\circ} \mathrm{C}$ in an oven overnight. The dried films were then weighed again. The water mass fraction in the water-loaded films was determined from the mass difference between the wet and dry samples.

\subsection{Measurements of the diffusion kinetics}

The diffusion kinetics was investigated by monitoring the rate of coloration of the PVA matrix films. The coloration of the sensor is a result of a reaction of colorless LMB (leuco methylene blue) with diffusing oxygen to MB (Marek et al., 2013). Thus, the formation of MB and consequently the increase in the MB absorbance correlates with the diffusion kinetics of oxygen. The experiments were performed at a constant $\mathrm{RH}$ and temperature in the above-mentioned temperature and climate test chamber WKL 34/40. The MB absorbance in the indicator/polymer system was monitored with a Specord 205 (Analytik Jena AG, Germany) UV-Vis (visible) spectrophotometer. The details of the method were already described in Marek et al. (2013).

\section{Compensation for the influence of temperature and humidity on oxygen diffusion}

\subsection{Temperature compensation}

The temperature dependence of the oxygen diffusion coefficient in the PVA matrix can be described using the Arrhenius
Eq. (1).

$D_{\mathrm{O}_{2} / \mathrm{PVA}}=D_{0} \exp \left(-\frac{E_{\mathrm{a}}}{\mathrm{RT}}\right)$,

where $E_{\mathrm{a}}\left(\mathrm{kJ} \mathrm{mol}^{-1}\right)$ is the activation energy of the diffusion and $D_{0}$ is the frequency factor. Plotting the logarithm of the oxygen diffusion coefficient in the PVA matrix

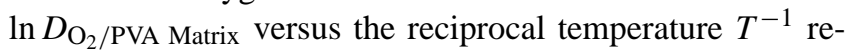
sults in a line whereas the slope of this line gives the activation energy of the oxygen diffusion in the PVA matrix.

To compensate for the increase in oxygen diffusion with increasing temperature, iron particles were added to the PVA, resulting in a PVA/iron composite matrix. A homogeneous and reproducible distribution of the iron particles in the PVA/iron composite matrix could be achieved without agglomeration, shown in Fig. 1. At higher temperatures, the iron particles are more rapidly oxidized by the diffusing oxygen. Therefore, more oxygen is consumed by the oxidation of the iron surface (iron corrosion), and the reaction with LMB is reduced. At low temperatures, the iron oxidation in an ironbased oxygen scavenger is slow; e.g., the oxygen absorptionrate constant at $313.15 \mathrm{~K}$ is twice of that at $293.15 \mathrm{~K}$ (Charles et al. 2006). Thus, the influence of oxygen consumption on the diffusion-reaction system is negligible.

Iron corrosion has been intensively investigated in recent decades (e.g., Kaesche, 1990; Stalder, 1974; Foltynowicz et al., 2002) and it is know that, besides oxygen, water is also necessary for the iron oxidation. Since water is always present in the PVA matrix in this study, iron corrosion is only limited by the diffusion rate and solubility of oxygen in the PVA matrix. 


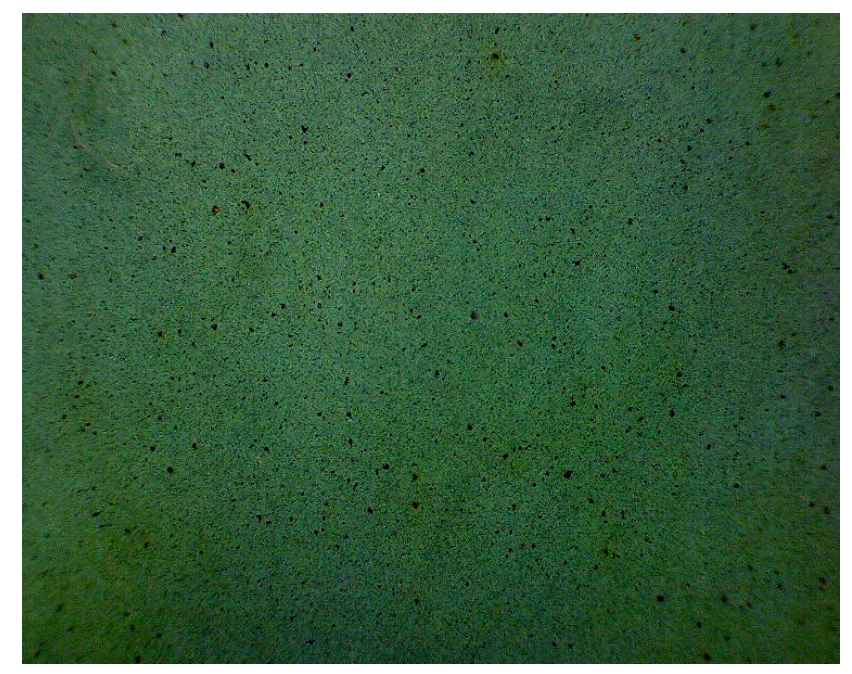

Figure 1. Image of distribution of iron particles in the PVA/iron film recorded with a DigiMicro 2.0 Scale Microscope camera, dnt $\mathrm{GmbH}(20 \times$ magnification).

As shown in Fig. 2, the oxidation of iron in an aqueous environment is a redox process with an anode reaction,

$\mathrm{Fe} \rightarrow \mathrm{Fe}^{2+}+2 e^{-}$,

and a cathode reaction,

$0.5 \mathrm{O}_{2}+\mathrm{H}_{2} \mathrm{O}+2 e^{-} \rightarrow 2 \mathrm{OH}^{-}$.

Finally, iron oxide (rust, $\mathrm{FeO}(\mathrm{OH})$ and $\mathrm{Fe}_{2} \mathrm{O}_{3}$ ) are formed from the $\mathrm{Fe}^{2+}$ ions (Eqs. 4-6):

$\mathrm{Fe}^{2+}+0.5 \mathrm{O}_{2}+\mathrm{H}_{2} \mathrm{O} \rightarrow \mathrm{Fe}(\mathrm{OH})_{2}$,

$\mathrm{Fe}(\mathrm{OH})_{2}+0.5 \mathrm{O}_{2} \rightarrow 2 \mathrm{FeO}(\mathrm{OH})+\mathrm{H}_{2} \mathrm{O}$

$2 \mathrm{FeO}(\mathrm{OH})+2 \mathrm{H}_{2} \mathrm{O} \rightarrow \mathrm{Fe}_{2} \mathrm{O}_{3}+3 \mathrm{H}_{2} \mathrm{O}$.

At atmospheric conditions, the iron oxide forms a very thin (1-4 nm), nonporous, dense and adherent oxide layer, which surrounds the iron particles (Wanner, 2010; Leygraf and Graedel, 2000). This layer has protective properties against further oxidation. Through this oxide layer the oxidation of the residual metal particles is limited; thus, the temperature compensation is limited. To prevent the formation of the oxide on the iron surface, Wanner (2010) successfully added $\mathrm{NaCl}$ to polymer composites of iron particles and polypropylene. By doing that, the protective layer was destroyed and new $\mathrm{Fe}^{2+}$ ions became available. Thus, in this work, $\mathrm{NaCl}$ was also added to the PVA matrix resulting in a PVA/iron/ $\mathrm{NaCl}$ composite matrix. In this way, the function of the temperature compensator can be accelerated and maintained for a long time.

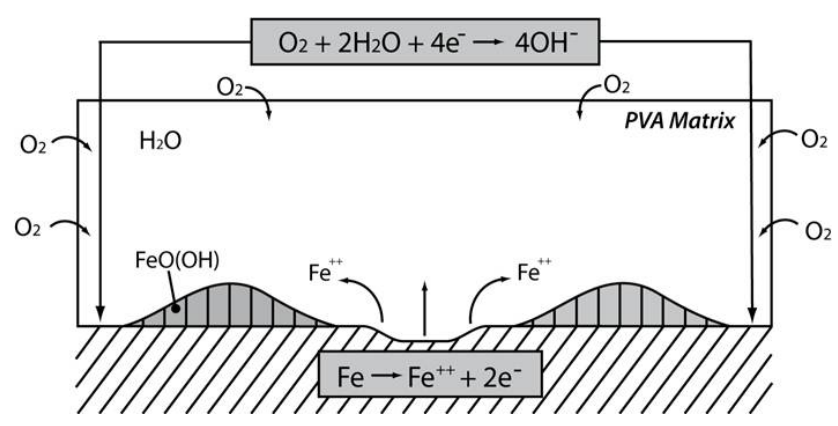

Figure 2. Oxidation of the iron surface in a water-loaded PVA/iron composite matrix.

The addition of $\mathrm{NaCl}$ however also changes the properties of polymer matrix, such as the water sorption behavior (Naeem and Sadowski, 2010; Sanahuja et al., 2012). Changing the water content also changes the oxygen concentration in the polymer matrix. This in turn has an effect on the iron corrosion and the oxygen diffusion in the PVA/iron/ $/ \mathrm{NaCl}$ composite matrix.

For practical applications, it is essential that the iron mass fraction of $0.01-0.05$ in the $\mathrm{PVA} / \mathrm{iron} / \mathrm{NaCl}$ composite matrix ensures the temperature compensation for several years (time was calculated using the oxygen-consumption capacity of elementary iron from Wanner, 2010). Furthermore it is not expected that iron or iron-oxidation products affect the oxygen diffusion or water content in the PVA/iron $/ \mathrm{NaCl}$ composite matrix, since the absolute amount of oxygen is very low compared to the absolute amount of water in the matrix. Thus, the amount of the resulting oxidation products as well as water in Eqs. (4-6) is also very low.

\subsection{Humidity compensation}

The oxygen diffusion coefficient in the water-loaded PVA matrix strongly depends on the water mass fraction in the PVA matrix (see Fig. 3) which itself is a function of RH (see Table 1). The oxygen diffusion coefficient in the waterloaded PVA matrix is less than $1 \times 10^{-13} \mathrm{~m}^{2} \mathrm{~s}^{-1}$ at $298.15 \mathrm{~K}$ for water mass fractions $\left(w_{\text {water }}\right)$ smaller than 0.1 and increases with increasing water mass fraction in the PVA matrix to about $2 \times 10^{-9} \mathrm{~m}^{2} \mathrm{~s}^{-1}$ at $298.15 \mathrm{~K}\left(w_{\text {water }}=1.0\right)$.

To decrease the humidity dependence, a certain amount of PVA in the PVA matrix was replaced by silicone particles resulting in novel PVA/silicone composite matrix. Since these silicone particles practically do not absorb water (the maximum water sorption in silicone $\left(w_{\text {water }}\right)$ is less than 0.01 at $25^{\circ} \mathrm{C}$ ), the total amount of water in the $\mathrm{PVA} /$ silicone composite matrix is smaller than that in pure PVA. The PVA/silicone composite matrix is thus less influenced by humidity. In a hypothetical PVA-free system, the oxygen diffusion finally does not depend on the water content anymore since the oxygen diffusion coefficient in silicone $\left(1.7 \times 10^{-9} \mathrm{~m}^{2} \mathrm{~s}^{-1}\right.$; Nunes, 2001) compares to the value in 


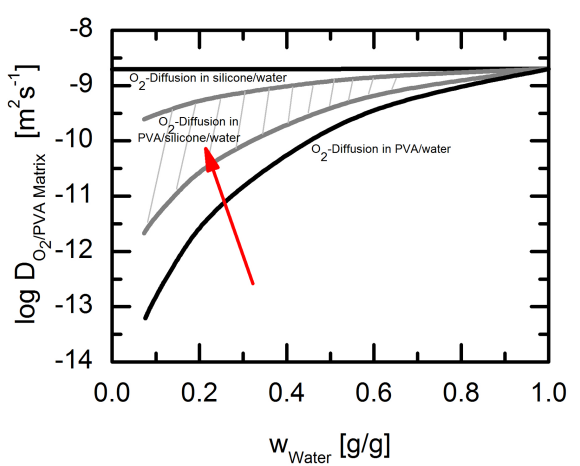

Figure 3. Schematic drawing of the oxygen diffusion coefficient as a function of the water mass fraction in the PVA/silicone composite matrix. The arrow shows increasing amounts of silicone particles in the PVA/silicone composite matrix. The hatching shows the region where oxygen diffusion in the PVA/silicone composite matrix is only little influenced by the water content.

pure water $\left(2 \times 10^{-9} \mathrm{~m}^{2} \mathrm{~s}^{-1}\right.$ at $298.15 \mathrm{~K}$; Tse and Sandall, 1979; Han and Bartels, 1996).

Figure 3 also schematically shows the change of oxygen diffusion as a function of silicone content in the PVA/silicone composite matrix. The higher the silicone mass fraction in the PVA/silicone composite matrix, the lower is the influence of the water content on oxygen diffusion. In this work, the silicone mass fraction in the water-loaded PVA/silicone composite matrix varied between was 0.05 and 0.25 .

\section{Modeling}

\subsection{Modeling the diffusion-controlled oxidation of LMB in the PVA matrix}

To describe the diffusion-controlled oxidation of LMB in the PVA matrix, we used a model which combines Fick's second law and the reaction kinetics of LMB with diffusing oxygen as already proposed in Marek et al. (2013).

The reaction for LMB oxidation is represented by Eq. (7).

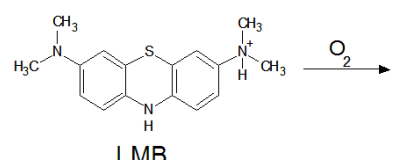

LMB

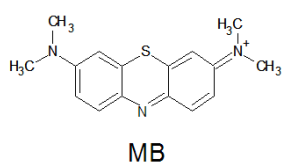

MB
The change of oxygen concentration by LMB oxidation and oxygen diffusion in the PVA matrix is described by Eq. (8).

$\frac{\partial c_{\mathrm{O}_{2}}}{\partial t}=\nabla \cdot\left(D_{\mathrm{O}_{2}} \nabla c_{\mathrm{O}_{2}}\right)+r$,

where $D_{\mathrm{O}_{2}}$ is the oxygen diffusion coefficient in the PVA matrix, and $r$ is the reaction rate of the oxidation according to Eq. (7). The reaction rate was already determined in Marek et al. (2013) as a function of the reaction-rate constant $k$ and the oxygen and LMB concentrations, respectively:

$r=-k \cdot c_{\mathrm{O}_{2}}^{1.2} \cdot c_{\mathrm{LMB}}^{0.8}$.
The reaction-rate constant $k$ depends on temperature and was also determined in Marek et al. (2013). The temperature dependence of $k$ is defined by the Arrhenius Eq. (10).

$k=k_{0} \cdot \exp \left(-\frac{E_{\mathrm{a}}}{\mathrm{RT}}\right)$,

where $E_{\mathrm{a}}$ is the activation energy of the reaction (i.e., $39 \mathrm{~kJ} \mathrm{~mol}^{-1}$ ) and $k_{0}$ is the frequency factor (approximately $3000000 \mathrm{~m}^{3} \mathrm{~mol}^{-1} \mathrm{~s}^{-1}$ ) (Marek et al., 2013).

To model the diffusion process, the polymer film was assumed to have a rectangular geometry with a defined layer thickness. In this work films of 170 and $180 \mu \mathrm{m}$ thickness were used.

The initial oxygen concentration in the film was assumed to be zero. The oxygen concentration at the polymer surface $c_{0}\left(\mathrm{~mol} \mathrm{~m}^{-3}\right)$ was assumed to be the equilibrium oxygen solubility for a defined water mass fraction in the PVA matrix, obtained from Marek et al. (2013).

$c(t=0, x=0)=c_{0}$

Given a particular oxygen diffusion coefficient in the PVA matrix $D_{\mathrm{O}_{2}}$, Eqs. (8)-(10) can be solved simultaneously, e.g., by applying the finite element method (FEM) in the software COMSOL Multiphysics. This leads to concentration profiles of oxygen, $\mathrm{LMB}$, and $\mathrm{MB}$ as a function of the position in the polymer film and of time. The value of $D_{\mathrm{O}_{2}}$ was then found by fitting the modeled MB-concentration profiles in the PVA film to the measured ones.

\subsection{Modeling the temperature compensation}

To model the temperature compensation in the PVA/iron/ $\mathrm{NaCl}$ composite matrix, the model described above was expanded as explained in the following.

The formation of the iron ions at the metal surface is caused by diffusing oxygen as a result of iron oxidation. The formation of the iron ions, in turn, leads to the formation of corrosion elements, as shown in Fig. 2 (Evans and Hoar, 1932; Guilminot et al., 2002). The corrosion is proportional to the amount of oxygen dissolved in the PVA matrix. The formation of $\mathrm{Fe}^{2+}$ ions is thus linked to the oxygen concentration, and the corrosion rate is described by Eq. (12).

$\frac{\partial c_{\mathrm{F}^{2+}}}{\partial t}=k_{\text {corrosion }} c_{\mathrm{O}_{2}}$,

where $k_{\text {corrosion }}$ is the corrosion-rate constant for the formation of $\mathrm{Fe}^{2+}$ ions at the metal surface. The reaction kinetics is valid for oxygen concentrations up to the maximum oxygen solubility in water at ambient conditions.

The $\mathrm{Fe}^{2+}$ ions are consumed in reactions with oxygen (Eqs. 4-6) and further converted into $\mathrm{Fe}^{3+}$. The reaction rate for the latter reaction is given by Eq. (13) (Trapp and Millero, 2007).

$\frac{\partial c_{\mathrm{Fe}^{2+}}}{\partial t}=-k\left(T, c_{\mathrm{NaCl}}\right) c_{\mathrm{Fe}^{2+}} c_{\mathrm{O}_{2}}$, 
where $k\left(T, c_{\mathrm{NaCl}}\right)$ is the reaction-rate constant and mainly depends on the temperature and salt concentration. Combining Eqs. (8-10), describing the oxygen diffusion in the PVA matrix, and Eqs. (12) and (13), describing the iron corrosion, leads to the following expression for the change in the oxygen concentration in the PVA/iron/ $\mathrm{NaCl}$ composite film:

$$
\begin{aligned}
\frac{\partial c_{\mathrm{O}_{2}}}{\partial t} & =\nabla \cdot\left(D_{\mathrm{O}_{2}} \nabla c_{\mathrm{O}_{2}}\right)-k \cdot c_{\mathrm{O}_{2}}^{1.2} \cdot c_{\mathrm{LMB}}^{0.8}-k_{\text {corrosion }} c_{\mathrm{O}_{2}} \\
& -k\left(T, c_{\mathrm{NaCl}}\right) c_{\mathrm{Fe}^{2+}} c_{\mathrm{O}_{2}} .
\end{aligned}
$$

Equation (14) was solved in COMSOL using diffusion coefficients of oxygen in the PVA matrix determined within this work.

\subsection{Modeling the humidity compensation}

For modeling the influence of silicone particles on the overall oxygen diffusion, the polymer film was considered to contain silicone particles (of $5 \mu \mathrm{m}$ diameter). The number of silicone particles refers to the final volume fraction of silicone in the water-loaded PVA/silicone composite films and was determined from the silicone mass fraction in the water-loaded PVA/silicone composite films (in this work up to 0.25$)$. In this work the number of silicone particles varied between $9.5 \times 10^{14}$ and $4.5 \times 10^{15}$ particles per cubic meter of water-loaded PVA/silicone composite matrix. Since LMB does not dissolve in silicone, the oxidation of LMB was only assumed to proceed in the PVA matrix. The boundary conditions for the film were as defined in Sect. 4.1. Using again the FEM in the software COMSOL Multiphysics, Eqs. (8-10) were solved simultaneously for the PVA/silicone composite film containing a defined number of silicone particles. The oxygen diffusion coefficient in silicone was assumed to be $1.7 \times 10^{-9} \mathrm{~m}^{2} \mathrm{~s}^{-1}$ (Nunes, 2001). For oxygen diffusion in the water-loaded PVA matrix, diffusion coefficients were used as determined in this work. Using these values, the $\mathrm{LMB}, \mathrm{MB}$, and $\mathrm{O}_{2}$ concentration profiles in the $\mathrm{PVA} /$ silicone composite film were modeled.

\section{Results and discussion}

\subsection{Influence of temperature on oxygen diffusion in a reactive PVA matrix}

\subsubsection{Temperature dependence of oxygen diffusion coefficients}

Figure 4 shows temperature-dependent $\mathrm{MB}$ concentration profiles in the PVA films containing different amounts of water. The MB concentration profiles were modeled using oxygen diffusion coefficients in the PVA matrix as shown in Table 2. The oxygen concentrations in the PVA matrix were obtained from Marek et al. (2013) and are shown in Table 1.

Figure $4 \mathrm{a}$ shows the obtained MB concentration profiles for a water mass fraction in the PVA matrix of 0.170 . The a)

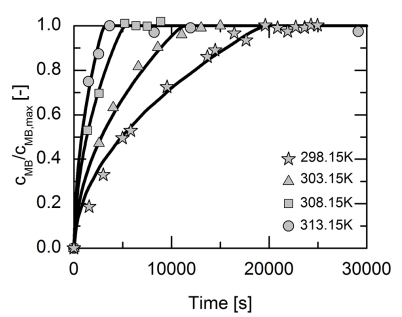

c)

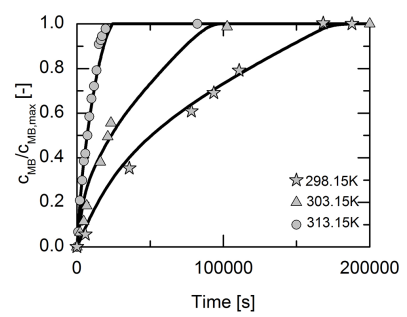

b)

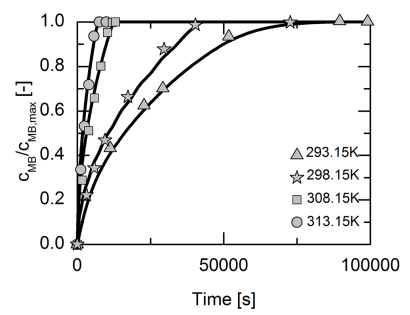

d)

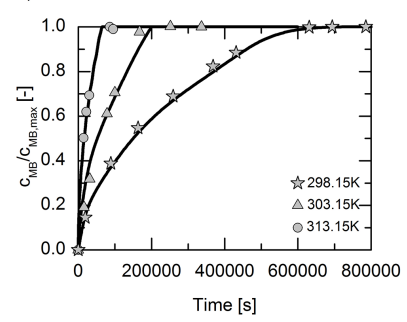

Figure 4. MB concentration profiles in PVA films of $170 \mu \mathrm{m}$ thickness at temperatures between 293.15 and $313.15 \mathrm{~K}$. The water mass fractions are 0.170 (a), 0.133 (b), 0.110 (c) and 0.089 (d). Symbols are experimental data and lines are modeled profiles using oxygen diffusion coefficients in the PVA film from Table 2.

oxygen diffusion coefficient in the PVA film increases by approximately a factor of 10 from $1.4 \times 10^{-12} \mathrm{~m}^{2} \mathrm{~s}^{-1}$ at $298.15 \mathrm{~K}$ to $1.2 \times 10^{-11} \mathrm{~m}^{2} \mathrm{~s}^{-1}$ at $313.15 \mathrm{~K}$.

A very similar behavior was observed for PVA films with water mass fractions of 0.133 and 0.110 . The corresponding measured and modeled MB concentration profiles are shown in Fig. 4b and c. For an even lower water mass fraction (0.089), the oxygen diffusion coefficient even increases by a factor of 13 in a similar temperature range (Fig. 4d).

From these results it can be seen that increasing the temperature by about $5 \mathrm{~K}$ results in a doubling of the oxygen diffusion coefficient in the PVA matrix. This dependence was observed for all of the PVA matrices investigated in this study regardless of the water content.

The activation energy of the oxygen diffusion in the PVA matrix was determined for the four water mass fractions in the PVA matrix according to Eq. (1). The plots are shown in Fig. 5. The values for $E_{\mathrm{a}}$ decrease from $129 \mathrm{~kJ} \mathrm{~mol}^{-1}$ at a water mass fraction of 0.089 to $109 \mathrm{~kJ} \mathrm{~mol}^{-1}$ at a water mass fraction of 0.170 . This decrease of activation energy with increasing water mass fraction in the PVA matrix is caused by the fact that the activation energy for oxygen diffusion in pure water is significantly lower (approximately $17-19 \mathrm{~kJ} \mathrm{~mol}^{-1}$; Han and Bartels, 1996; Ferrell and Himmelblau, 1967) than that determined in this work for oxygen diffusion in the PVA matrix. 
Table 2. Oxygen diffusion coefficients in a PVA matrix as a function of water mass fraction in the PVA matrix and of temperature.

\begin{tabular}{rrr}
\hline $\begin{array}{r}\text { Water mass fraction } \\
\text { in PVA matrix }\end{array}$ & $\begin{array}{r}\text { Temperature } \\
(\mathrm{K})\end{array}$ & $\begin{array}{r}\text { Oxygen diffusion } \\
\text { coefficient } D_{\mathrm{O}_{2}}\left(\mathrm{~m}^{2} \mathrm{~s}^{-1}\right)\end{array}$ \\
\hline 0.170 & 298.15 & $1.4 \times 10^{-12}$ \\
0.170 & 303.15 & $3.0 \times 10^{-12}$ \\
0.170 & 308.15 & $7.0 \times 10^{-12}$ \\
0.170 & 313.15 & $1.2 \times 10^{-11}$ \\
0.133 & 293.15 & $5.0 \times 10^{-13}$ \\
0.133 & 298.15 & $8.0 \times 10^{-13}$ \\
0.133 & 308.15 & $3.2 \times 10^{-12}$ \\
0.133 & 313.15 & $6.5 \times 10^{-12}$ \\
0.110 & 298.15 & $2.2 \times 10^{-13}$ \\
0.110 & 303.15 & $5.0 \times 10^{-13}$ \\
0.110 & 313.15 & $2.3 \times 10^{-12}$ \\
0.089 & 298.15 & $8.5 \times 10^{-14}$ \\
0.089 & 303.15 & $2.6 \times 10^{-13}$ \\
0.089 & 313.15 & $1.1 \times 10^{-12}$ \\
0.073 & 298.15 & $5.4 \times 10^{-14}$ \\
\hline
\end{tabular}

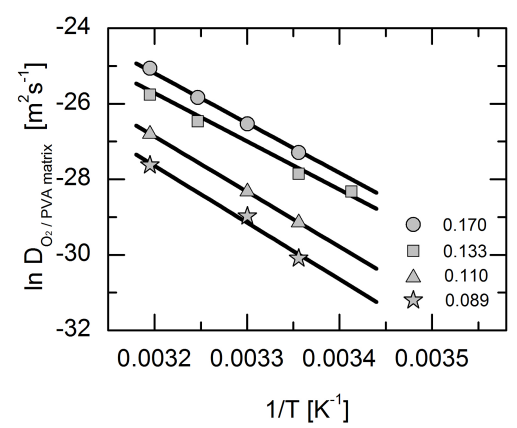

Figure 5. Arrhenius plot of the oxygen diffusion coefficients in the PVA matrix for water mass fractions in the PVA matrix of 0.170 , $0.133,0.110$, and 0.089 , respectively.

\subsubsection{Temperature compensation of oxygen diffusion}

The influence of the iron ions generated from the iron particles on the diffusion-reaction system was measured for an iron mass fraction of 0.045 in the PVA/iron composite matrix. The results for a PVA/iron composite film of $180 \mu \mathrm{m}$ thickness at $313.15 \mathrm{~K}$ and $80 \% \mathrm{RH}$ are shown in Fig. 6 . As can be seen, the influence of iron particles on the measured/modeled MB concentration profile is very small.

The generation of iron ions from iron particles and thus the corrosion process can be accelerated by the addition of salts, e.g., $\mathrm{NaCl}$ (Wanner, 2010). Therefore, the iron influence in the presence of $\mathrm{NaCl}$ (mass fraction of 0.01) was also investigated in this work.

The resulting $\mathrm{MB}$ concentration profiles for iron mass fractions of $0.01,0.02$, and 0.06 at $313.15 \mathrm{~K}$ and $80 \% \mathrm{RH}$ are shown in Fig. 7a. For comparison, Fig. 7a also shows measured and modeled MB profiles in the PVA films in the absence of iron and $\mathrm{NaCl}$ at the same conditions. It can be

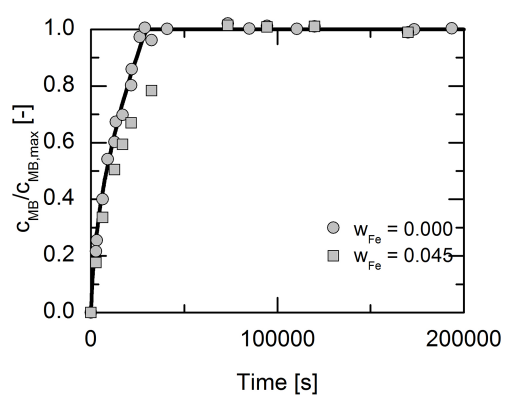

Figure 6. Influence of iron particles (iron mass fraction in the PVA/iron composite matrix of 0.045 ) on the MB concentration profile in PVA/iron composite films of $180 \mu \mathrm{m}$ thickness at $313.15 \mathrm{~K}$ and $\mathrm{RH}$ of $80 \%$. The symbols represent experimental data and the line is the modeling of the MB concentration profile in the absence of iron.

seen that iron mass fractions between 0.01 and 0.06 extend the time needed for reaching the final MB concentrations in the film by a factor of between 3 and 6 . The reaction of oxygen with LMB is reduced due to the consumption of oxygen for iron oxidation (Eqs. 2-6). The higher the iron concentration, the more oxygen is consumed and the oxidation of LMB is reduced.

The temperature compensation of oxygen diffusion was also investigated at a lower temperature. Figure $7 \mathrm{~b}$ shows the MB concentration profiles for iron mass fractions of 0.015 and 0.06 at $298.15 \mathrm{~K}$. The concentration profile in the absence of iron and $\mathrm{NaCl}$ is again shown for comparison. It can be seen that at the lower temperature of $298.15 \mathrm{~K}$, the addition of iron to the PVA matrix with or without adding $\mathrm{NaCl}$ has only a small effect on oxygen diffusion and therewith on the MB profiles.

A comparison of the MB concentration profile for an iron mass fraction of 0.06 in Fig. 7a at $313.15 \mathrm{~K}$ with the MB concentration profile for the same iron mass fraction at $298.15 \mathrm{~K}$ in Fig. $7 \mathrm{~b}$ shows that the concentration profiles are nearly the same. Thus, the oxidation of LMB in the PVA composite films can be limited at higher temperatures, whereas at lower temperatures the influence of iron particles and $\mathrm{NaCl}$ on the oxygen diffusion is not observable.

Since $\mathrm{NaCl}$ obviously has a huge influence on the corrosion of the iron particles, and consequently on the diffusion-reaction system in the $\mathrm{PVA} / \mathrm{iron} / \mathrm{NaCl}$ composite matrix, the influence of $\mathrm{NaCl}$ on the diffusion-reaction system was investigated separately. The influence of the $\mathrm{NaCl}$ concentration on the MB concentration profiles in the PVA/iron/ $\mathrm{NaCl}$ composite films of $180 \mu \mathrm{m}$ thickness for an iron mass fraction of 0.05 at $313.15 \mathrm{~K}$ and $80 \% \mathrm{RH}$ is shown in Fig. 8. Again, the modeled MB concentration profile for a PVA film of $180 \mu \mathrm{m}$ thickness in the absence of iron and $\mathrm{NaCl}$ is also shown for comparison.

The corrosion increases with increasing $\mathrm{NaCl}$ mass fraction in the PVA/iron/ $\mathrm{NaCl}$ composite films resulting in reduced reaction of oxygen with LMB. However, for a $\mathrm{NaCl}$ 
Table 3. Corrosion-rate constants as a function of $\mathrm{NaCl}$ content for an iron mass fraction of 0.05 in the PVA/iron/ $/ \mathrm{NaCl}$ composite matrix at $313.15 \mathrm{~K}$.

\begin{tabular}{llllll}
\hline $\mathrm{NaCl}$ mass fraction & 0.000 & 0.005 & 0.010 & 0.015 & 0.020 \\
\hline Corrosion-rate constant $\left(\mathrm{s}^{-1}\right)$ & 0.000 & 0.006 & 0.022 & 0.045 & 0.033 \\
\hline
\end{tabular}

a)

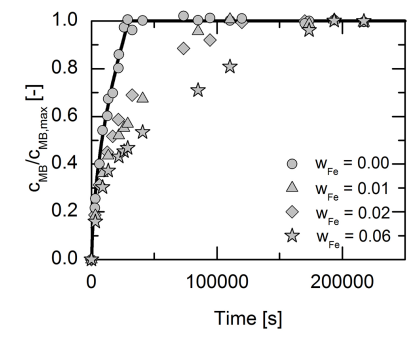

b)

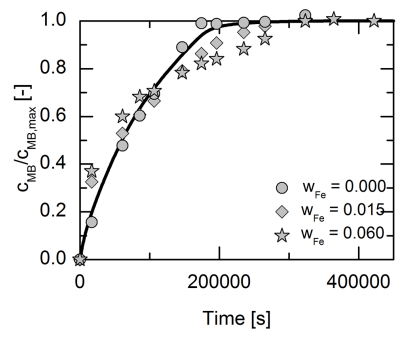

Figure 7. $\mathrm{MB}$ concentration profiles in the PVA/iron/NaCl composite films of $180 \mu \mathrm{m}$ thickness at $80 \% \mathrm{RH}$, a $\mathrm{NaCl}$ mass fraction of 0.01 and iron mass fractions of $0.01,0.02$, and 0.06 at $313.15 \mathrm{~K}$ (a), and iron mass fractions of 0.015 and 0.06 at $298.15 \mathrm{~K}$ (b). Symbols represent experimental data and the lines are the modeled MB concentration profiles in the absence of iron and $\mathrm{NaCl}$.

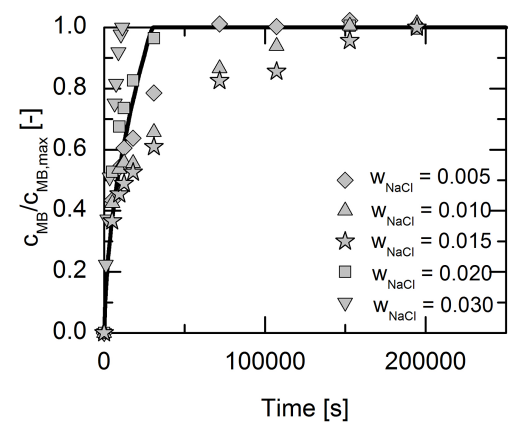

Figure 8. Influence of the $\mathrm{NaCl}$ mass fraction in the PVA composite films with an iron mass fraction of 0.05 and $180 \mu \mathrm{m}$ thickness at $313.15 \mathrm{~K}$ and $\mathrm{RH}$ of $80 \%$. The symbols represent experimental data; the line is the modeling of the MB concentration profile in the absence of iron and $\mathrm{NaCl}$.

mass fraction higher than 0.02 the oxidation of LMB significantly increases. The slowest oxidation of LMB in the $\mathrm{PVA} / \mathrm{iron} / \mathrm{NaCl}$ composite film was achieved for a $\mathrm{NaCl}$ mass fraction of 0.015 . For a $\mathrm{NaCl}$ mass fraction higher than 0.02, the diffusion rate rises due to the increased water sorption of the PVA films containing $\mathrm{NaCl}$ compared to the $\mathrm{NaCl}$-free films (see Appendix A2). Consequently, temperature compensation is not possible for $\mathrm{NaCl}$ mass fractions higher than 0.02 .

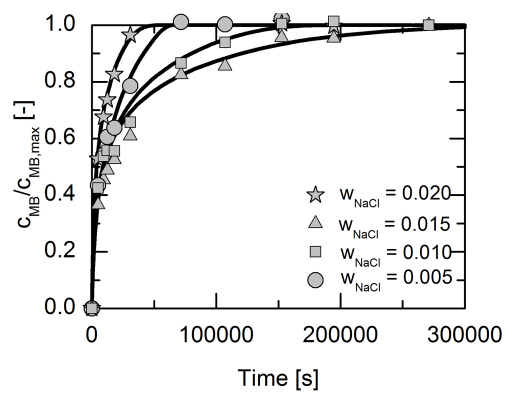

Figure 9. MB concentration profiles in PVA composite films of $180 \mu \mathrm{m}$ thickness for an iron mass fraction of 0.05 and a $\mathrm{NaCl}$ mass fraction between 0 and 0.02 at $80 \% \mathrm{RH}$ and $313.15 \mathrm{~K}$. Symbols are experimental data and lines are modeled concentration profiles using oxygen diffusion coefficients from Table 2 and the corrosionrate constants from Table 3 .

\subsubsection{Modeling of the temperature compensation}

The aim of modeling was to mathematically describe the temperature compensation and to predict the oxygen diffusion as a function of the desired LMB and iron concentrations. For modeling, the oxygen solubility (Table 1) and oxygen diffusion coefficients according to the higher water mass fractions in the PVA matrix (Appendix A2) caused by $\mathrm{NaCl}$ addition were used as determined above. The reaction-rate constants for the iron oxidation were fitted to the measured MB concentration profiles and are shown in Table 3.

The modeling of the MB concentration profiles in PVA composite films of $180 \mu \mathrm{m}$ thickness with an iron mass fraction of 0.05 and $\mathrm{NaCl}$ mass fractions of $0.005,0.010,0.015$, and 0.02 are shown in Fig. 9. It becomes obvious that the implemented model (see Sect. 4.3) is able to reproduce the experimental results.

With increasing $\mathrm{NaCl}$ mass fractions in the PVA composite matrix, the obtained reaction-rate constants (Table 3 ) for the iron oxidation increase from $0.006 \mathrm{~s}^{-1}$ for a $\mathrm{NaCl}$ mass fraction of 0.05 up to approximately $0.045 \mathrm{~s}^{-1}$ for a $\mathrm{NaCl}$ mass fraction of 0.015 . For higher $\mathrm{NaCl}$ mass fractions, the reaction-rate constant again decreases. 


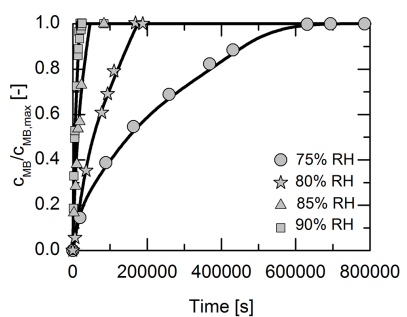

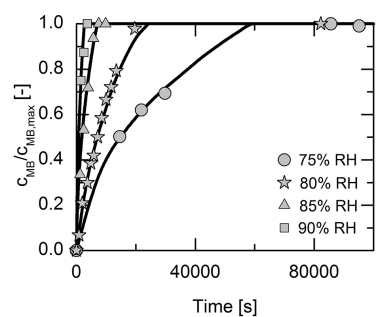

Figure 10. MB concentration profiles in PVA films of $170 \mu \mathrm{m}$ thickness as a function of RH at $298.15 \mathrm{~K}$ (a) and at $313.15 \mathrm{~K}$ (b). Symbols are experimental data and lines are modeled profiles using oxygen diffusion coefficients in the PVA film from Table 2.

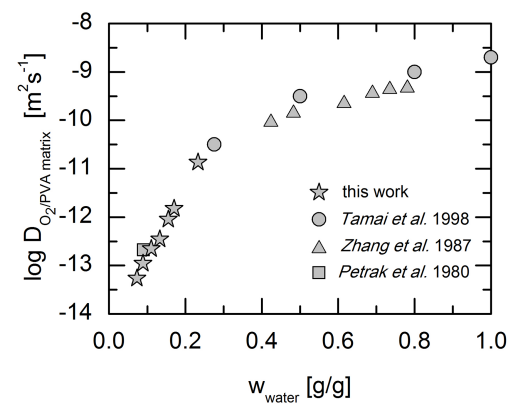

Figure 11. Oxygen diffusion coefficients $(D)$ in the PVA matrix as a function of the water mass fraction in the PVA matrix at $298.15 \mathrm{~K}$.

\subsection{Influence of humidity on oxygen diffusion in a reactive PVA matrix}

\subsubsection{Humidity dependence of oxygen diffusion coefficients}

In addition to the influence of temperature on the oxygen diffusion in the PVA matrix, in this work the influence of the RH was investigated. The measured and modeled MB concentration profiles are shown for $298.15 \mathrm{~K}$ in Fig. 10a and for $313.15 \mathrm{~K}$ in Fig. 10b. As can be seen, the oxygen diffusion very strongly depends on the RH of the surrounding atmosphere.

The obtained oxygen diffusion coefficients in the PVA matrix are shown in Fig. 11 as a function of the water mass fraction in the PVA matrix. The data obtained in this work are in good agreement with data reported in Zhang et al. (1987), Tamai and Tanaka (1998), and Petrak and Pitts (1980). A similar dependence of the diffusion coefficients of other gases (e.g., nitrogen and water vapor) on the water mass fraction in the PVA matrix was observed in Jack et al. (2011), Tamai and Tanaka (1998), and Lien et al. (2002). In addition, it was also shown in Lien et al. (2002), that the oxygen permeability, which is proportional to the solubility and diffusion coefficient, increases with increasing water mass fraction in the PVA matrix, which also confirms our data.

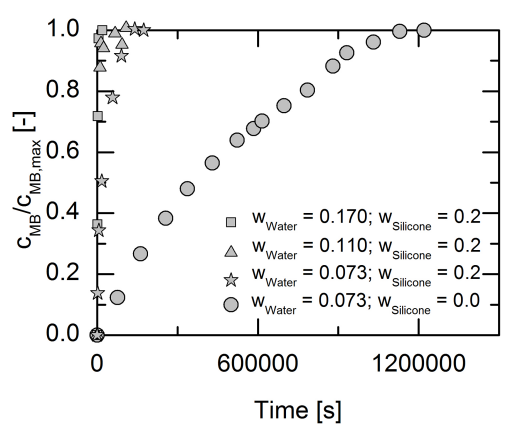

Figure 12. Effect of a silicone mass fraction of 0.2 in the PVA/silicone composite films of $170 \mu \mathrm{m}$ thickness on the MB concentration profile for different water mass fractions in the PVA matrix at $298.15 \mathrm{~K}$ (see correlation of water mass fraction and RH in Table 1).

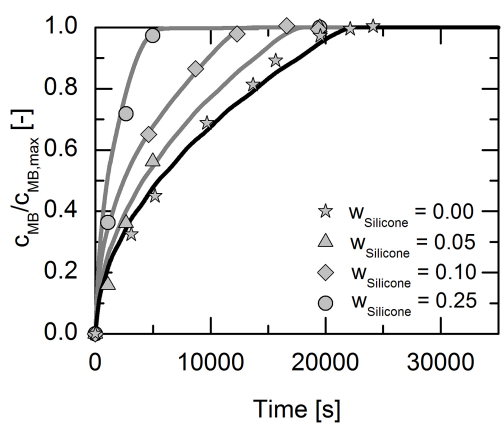

Figure 13. $\mathrm{MB}$ concentration profiles in PVA/silicone composite films of $170 \mu \mathrm{m}$ thickness at $298.15 \mathrm{~K}$ and $90 \% \mathrm{RH}$ for silicone mass fractions of $0.00,0.05,0.10$ and 0.25 . Symbols are experimental data and lines are modeled profiles using oxygen diffusion coefficients from Table 2. Gray lines show the modeling for films with silicone particles and the black line is the modeling for a film in absence of silicone.

\subsubsection{Humidity compensation - measurements and modeling}

The compensation of the humidity dependence of the diffusion-controlled oxidation of LMB in the PVA matrix was carried out by addition of silicone particles as described in Sect. 3.2. Figure 12 presents the measured MB concentration profiles in water-loaded PVA/silicone composite films of $170 \mu \mathrm{m}$ thickness at $298.15 \mathrm{~K}$ and various RH $(70,80,90 \%)$ for a silicone mass fraction of approximately 0.20 (equivalent to about $3.7 \times 10^{15}$ particles per cubic meter of the $\mathrm{PVA} /$ silicone composite matrix).

It can be seen that the MB concentration profiles in the $\mathrm{PVA} /$ silicone composite films exhibit very similar behavior for all examined water mass fractions whereas the MB concentration profile in the absence of silicone is quite different.

Thus, the MB concentration profiles in the presence of silicone compared to those without silicone (see also Fig. 10) 
Table 4. Composition (mass fractions) of the investigated PVA/silicone composite matrices at $298.15 \mathrm{~K}$ and $90 \% \mathrm{RH}$.

\begin{tabular}{lrrrr}
\hline$w_{\text {silicone }}$ & 0.25 & 0.10 & 0.05 & 0.00 \\
\hline$w_{\text {PVA }}$ & 0.6225 & 0.7470 & 0.7885 & 0.8300 \\
$w_{\text {water }}$ & 0.1275 & 0.1530 & 0.1615 & 0.1700 \\
\hline
\end{tabular}

are almost independent of RH, which shows that RH dependence could be reduced by adding silicone to the PVA matrix.

Since a silicone mass fraction of 0.2 has a huge influence on the oxygen diffusion in the PVA/silicone composite matrix, the influence of silicone on the diffusion-reaction system was further investigated. Figure 13 shows the measured MB concentration profiles in $170 \mu \mathrm{m}$ films at $90 \% \mathrm{RH}$ and $298.15 \mathrm{~K}$. The composition of the PVA/silicone composite matrices in Fig. 13 is given in Table 4. The higher the silicone mass fraction in the PVA/silicone composite matrix, the lower is the influence of the water on oxygen diffusion. Even for small silicone mass fractions $(<0.1)$ in the PVA/silicone composite matrix, a significant influence of silicone particles on the oxygen diffusion in a PVA/silicone composite was observed.

To model the measured MB concentration profiles in the PVA/silicone composite films, the model described in Sect. 4.3 was used. For each silicone mass fraction, the respective number of particles in the PVA/silicone composite films was calculated. For a silicone mass fraction of 0.05 the number of particles was $9.5 \times 10^{14}$ per cubic meter of the PVA/silicone composite matrix; for a silicone mass fraction of 0.10 the number of particles was $1.9 \times 10^{15} \mathrm{~m}^{-3}$ and for a silicone mass fraction of 0.25 the number was $4.5 \times 10^{15} \mathrm{~m}^{-3}$. All profiles were modeled with a constant oxygen diffusion coefficient of $1.4 \times 10^{-12} \mathrm{~m}^{2} \mathrm{~s}^{-1}$ in the water-loaded PVA matrix and a constant oxygen diffusion coefficient of $1.7 \times 10^{-9} \mathrm{~m}^{2} \mathrm{~s}^{-1}$ in silicone particles (see Sect. 4.3).

The modeling of the MB concentration profiles in the PVA/silicone composite films, shown in Fig. 13, is a pure prediction without any parameter fitting. As can be seen, the predictions agree very well with the experimental data.

\section{Design of a time-monitoring sensor with temperature and humidity compensation}

In a previous work (Marek et al., 2013) a time-monitoring oxygen sensor was proposed. This sensor is based on a diffusion-controlled oxygen reaction of the indicator system $\mathrm{MB} / \mathrm{LMB}$ and riboflavin embedded in a water-loaded PVA matrix. It can be used in packaging, sensors, and biotechnology applications, e.g., to indicate the shelf life of products after the first opening of the packaging cap. The main idea was to monitor the oxygen path in the PVA/indicator system
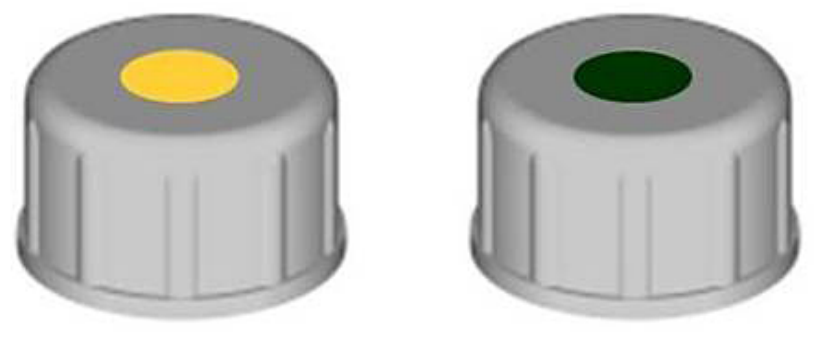

Figure 14. Time-monitoring sensor in a polymer bottle cap, that shows the expired shelf life time before (left) and after (right) first opening.

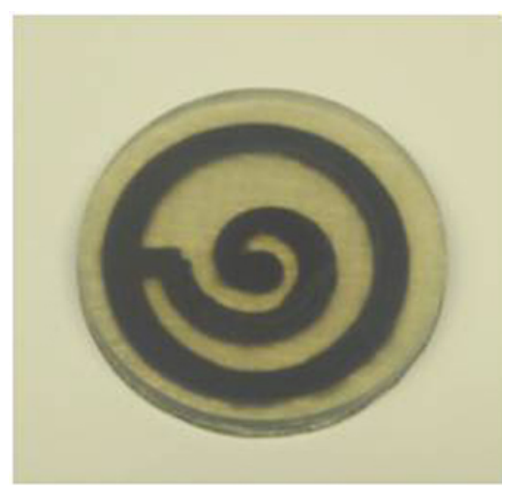

Figure 15. Spiral design of the oxygen path in the time-monitoring sensor.

embedded in the cap, which changes its color after a time corresponding to the product shelf life (see Fig. 14).

The indicated time directly depends on the oxygen path (diffusion length; Fig. 15), but also on temperature and water content in the PVA/polymer matrix.

As an example, to achieve the color change in the center of the cap (see Fig. 14) after the desired time of 6 weeks at a water mass fraction of 0.17 in the PVA matrix (corresponding to $90 \% \mathrm{RH}$ at $25^{\circ} \mathrm{C}$ ), the diffusion length in the cap has to be $0.9-1.1 \mathrm{~mm}$.

At changing conditions, e.g., RH $60 \%$ and $25^{\circ} \mathrm{C}$, the water mass fraction in the PVA matrix decreases from 0.17 to about 0.13 . To compensate for this loss of water, and thus the slower oxygen diffusion, silicone particles can be added. At a silicone mass fraction of about 0.2 in the PVA/silicone matrix, the oxygen diffusion again requires 6-8 weeks for the same distance of $0.9-1.1 \mathrm{~mm}$, whereas in the absence of silicone particles it would require 9-13 weeks. The ranges recommended for humidity compensation as well as the recommended silicone mass fraction in the PVA/silicone matrix are summarized in Table 5. These recommendations were estimated using the model described in Sect. 4.3 as well as the determined oxygen diffusion coefficients in the PVA matrix from Table 2. 
Table 5. Recommendations for temperature and humidity compensation.

\begin{tabular}{|c|c|c|}
\hline & Surrounding & Recommendation for compensation \\
\hline \multirow[t]{3}{*}{ Relative humidity } & $75-95 \%$ & compensation not required \\
\hline & $50-75 \%$ & recommended silicone mass fractions in the PVA/silicone matrix: of $0.2-0.3$ \\
\hline & $<50 \%$ & recommended silicone mass fraction in the PVA/silicone matrix: up to 0.5 \\
\hline \multirow[t]{4}{*}{ Temperature } & $20-25^{\circ} \mathrm{C}$ & compensation not required \\
\hline & $25-30^{\circ} \mathrm{C}$ & recommended iron mass fraction in the PVA/iron/ $\mathrm{NaCl}$ matrix: 0.01 \\
\hline & $30-35^{\circ} \mathrm{C}$ & recommended iron mass fraction in the $\mathrm{PVA} / \mathrm{iron} / \mathrm{NaCl}$ matrix: $0.02-0.03$ \\
\hline & $35-40^{\circ} \mathrm{C}$ & recommended iron mass fraction in the $\mathrm{PVA} / \mathrm{iron} / \mathrm{NaCl}$ matrix: $0.05-0.06$ \\
\hline
\end{tabular}

Analogously, iron particles and $\mathrm{NaCl}$ can be added to the PVA matrix to compensate for temperature changes in the surrounding. Recommended iron and $\mathrm{NaCl}$ amounts are shown in Table 5.

The compensations allow for the application of the sensor at different conditions of temperature and humidity and therewith in different environments and extend the application range of the sensor.

\section{Conclusions}

In this study, the oxygen diffusion in a water-loaded PVA matrix was studied as a function of temperature and water mass fraction in the PVA matrix. From the measured and modeled concentration profiles of MB in the PVA films, the oxygen diffusion coefficients in the PVA matrix were determined.

To describe the temperature dependence of the oxygen diffusion coefficients in the PVA matrix, the activation energy was determined using an Arrhenius plot. The activation energy depends on the water content and decreases from $129 \mathrm{~kJ} \mathrm{~mol}^{-1}$ for a water mass fraction of 0.089 to $109 \mathrm{~kJ} \mathrm{~mol}^{-1}$ for a water mass fraction of 0.170 . This decrease of activation energy with increasing water mass fraction in the PVA matrix is caused by the fact that the activation energy for oxygen diffusion in pure water is significantly lower than in polymers.

Moreover, the humidity dependence of the oxygen diffusion coefficients in the water-loaded PVA matrix was determined. The oxygen diffusion coefficient in the PVA matrix depends very strongly on the RH of the surrounding atmosphere and thus on the water mass fraction in the PVA matrix. It increases with increasing $\mathrm{RH}$.
For using the diffusion-reaction system in the PVA matrix, e.g., as freshness sensor for time monitoring in food packaging, constant oxygen diffusion must be guaranteed. For this reason, the temperature and particularly the humidity dependence have been compensated.

To compensate for the increase in oxygen diffusion with increasing temperature, iron particles were added to PVA, resulting in a PVA/iron composite matrix. At higher temperatures, the iron particles are more rapidly oxidized by the diffusing oxygen. Therefore, more oxygen is consumed by the oxidation of the iron surface (iron corrosion), and the reaction with the oxygen indicator LMB in the PVA/iron composite matrix is reduced. At low temperatures, the iron oxidation is slow. Thus, the influence of oxygen consumption on the diffusion-reaction system is negligible.

To compensate for the humidity dependence of oxygen diffusion in the PVA matrix, a certain amount of PVA in the water-loaded PVA matrix was replaced by silicone particles resulting in a novel PVA/silicone composite matrix. Since silicone particles do not absorb water, the total amount of water in the PVA/silicone composite matrix is smaller than that in the PVA matrix at the same RH, and the novel PVA/silicone composite matrix is thus less influenced by humidity.

Finally, both the influence of the iron particles as well as the influence of the silicone particles on the diffusioncontrolled oxidation of LMB were modeled successfully. The modeling results agree very well with the experimental data.

Using the experimental data determined in this work as well as the developed modeling, it is now possible to design and calibrate a freshness sensor for time monitoring which is based on oxygen diffusion through the packaging material. 


\section{Appendix A}

\section{A1 PC-SAFT parameters for PVA}

In this study, the pure-component PC-SAFT parameters - the segment diameter $\left(\sigma_{i}\right)$, the segment number $\left(m_{i}\right)$, and the dispersion-energy parameter $\left(\varepsilon_{i} / k\right)$ for PVA - and the binary interaction parameter for the mixture of water and PVA $k_{i j}$ of -0.039 were fitted simultaneously to the densities of aqueous PVA solutions at PVA mass fractions of $0.05,0.10$, and 0.15 , to VLE (vapor-liquid equilibrium) data obtained from Jack et al. (2011) and also to the density of pure PVA obtained from Zoller and Walsh (1995). The determined parameters are listed in Table A1. A detailed description of PCSAFT can be found in Gross and Sadowski (2002).

\section{A2 Water sorption in $\mathrm{PVA} / \mathrm{NaCl}$ films}

The water sorption in the PVA/ $\mathrm{NaCl}$ films was measured for different $\mathrm{NaCl}$ mass fractions as described in Sect. 2.3. The results are shown in Fig. A1. The water mass fraction in the $\mathrm{PVA} / \mathrm{NaCl}$ films significantly increases with added $\mathrm{NaCl}$. At $298.15 \mathrm{~K}$ and in the $\mathrm{RH}$ range of up to $95 \%$, the $\mathrm{PVA} / \mathrm{NaCl}$ films contained up to $50 \%$ more water than films without $\mathrm{NaCl}$.
Table A1. Pure-component PC-SAFT parameters for PVA.

\begin{tabular}{lrrr}
\hline Component & $m / M^{-1}\left(\mathrm{~mol} \mathrm{~g}^{-1}\right)$ & $\sigma(\AA)$ & $\varepsilon / k(\mathrm{~K})$ \\
\hline PVA & 0.080 & 2.39 & 219.18 \\
\hline
\end{tabular}

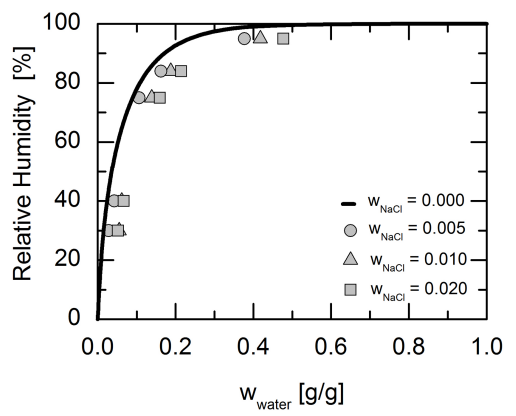

Figure A1. Water mass fraction in $\mathrm{PVA} / \mathrm{NaCl}$ films as a function of the $\mathrm{RH}$ of the surrounding atmosphere and of $\mathrm{NaCl}$ content in the films at $298.15 \mathrm{~K}$. Symbols are experimental data at various $\mathrm{NaCl}$ mass fractions $w_{\mathrm{NaCl}}$ of $0.005,0.010$, and 0.020 ; the line indicates the Flory-Huggins correlation in the absence of $\mathrm{NaCl}$ obtained from Jack et al. (2011). 
Acknowledgements. We gratefully acknowledge the Federal Ministry of Education and Research (BMBF) for supporting this project with grant 16SV3903. We also want to thank Jinwen Qin, Thomas Goetsch, and Frieda Sandberg for their help during the measurements and the modeling. We also thank Jan Kirchner from KISICO GmbH for preparing the CAD graphics and Thomas Haas for intensive and fruitful discussions.

Edited by: N.-T. Nguyen

Reviewed by: two anonymous referees

\section{References}

Charles, F., Sanchez, J., and Gontard, N.: Absorption kinetics of oxygen and carbon dioxide scavengers as part of active modified atmosphere packaging, Journal of Feed Engineering, 72, 1-7, 2006.

Evans, R. U. and Hoar, P. T.: The Velocity of Corrosion from the Electrochemical Standpoint. Part II, P. Roy. Soc., 137, 343-365, 1932.

Ferrell, T. R. and Himmelblau, M. D.: Diffusion Coefficients of Nitrogen and Oxygen in Water, J. Chem. Eng. Data, 12, 111-115, 1967.

Finch, C. A.: Poly(vinyl alcohol): Properties and Applications, Wiley, New York, 1973.

Foltynowicz, Z., Kozak, W. and Fiedorow, R.: Studies of Oxygen Uptake on $\mathrm{O}_{2}$-Scavengers Prepared from Different IronContaining Parent Substances, Packag. Technol. Sci., 15, 75-81, 2002.

Gross, J. and Sadowski, G.: Modeling polymer systems using the perturbed-chain statistical associating fluid theory equation of state, Ind. Eng. Chem. Res., 41, 1084-1093, 2002.

Guilminot, E., Dalard, F., and Degrigny, C.: Mechanism of Iron Corrosion in Water-Polyethylene Glycol (PEG 400) Mixtures, Corrosion Science, 44, 2199-2208, 2002.

Han, P. and Bartels, M. D.: Temperature Dependence of Oxygen Diffusion in $\mathrm{H}_{2} \mathrm{O}$ and $\mathrm{D}_{2} \mathrm{O}$, J. Phys. Chem., 100, 5597-5602, 1996.

Jack, S., Scharfer, P., Schabel, W., and Kind, M.: Water sorption in poly(vinyl alcohol) membranes: An experimental and numerical study of solvent diffusion in a crosslinked polymer, Chem. Eng. Process., 50, 543-550, 2011.

Kaesche, H.: Die Korrosion der Metalle, Springer-Verlag, Berlin, 1990.

Lange, J. and Wyser, Y.: Recent Innovations in Barrier Technologies for Plastic Packaging - a Review, Packag. Technol. Sci., 16, 149-158, 2003.

Leygraf, C. and Graedel, T. E.: Atmospheric Corrosion, John Wiley \& Sons, New York, 2000.

Lien, L., Fellows, C. M., Copeland, L., Hawkett, B. S., and Gilbert, R. G.: Water-binding and oxygen permeability in poly(vinyl alcohol) films, Aust. J. Chem., 55, 507-512, 2002.
Marek, P., Velasco-Veléz, J. J., Haas, T., Doll, T., and Sadowski, G.: Time-monitoring sensor based on oxygen diffusion in an indicator/polymer matrix, Sensor Actuat B-Chem., 178, 254-262, 2013.

Mills, A.: Oxygen Indicators and Intelligent Inks for Packaging Food, Chem. Soc. Rev., 12, 1003-1011, 2005.

Mokwena, K. K. and Tang, J.: Ethylene Vinyl Alcohol: A Review of Barrier Properties for Packaging Shelf Stable Foods, CRC Cr. Rev. Food Sci., 52, 640-650, 2012.

Naeem, S. and Sadowski, G.: pePC-SAFT: Modeling of Polyelectrolyte Systems. 1. Vapour-Liquid Equilibria, Fluid Phase Equilibr., 299, 84-93, 2010.

Nunes, S. P.: Membrane Technology in the Chemical Industry, Wiley-VCH, Weinheim, 2001.

Petrak, K. and Pitts, E.: Permeability of Oxygen through Polymers. II. The Effect of Humidity and Film Thickness on the Permeation and Diffusion Coefficients, J. Appl. Polym. Sci., 25, 879-886, 1980.

Phillips, C.: Review: Modified Atmosphere Packaging and its effects on the microbiological quality and safety of produce, Int. J. Food Sci. Tech., 31, 463-479, 1996.

Pritchard, G. J.: Poly(vinyl alcohol): Basic properties and uses, Taylor \& Francis, 1970.

Rooney, L. M.: Active Food Packaging, Blackie Academic \& Professional, 1995.

Sanahuja, S., Miesbauer, O., Reichmann, E., and Sängerlaub, S.: Modelling and numerical simulation of water vapour sorption kinetics in humidity regulating polypropylene films containing sodium chloride, European Multidisciplinary Society for Modelling and Simulation Technology -EUROSIS-; European Technology Institute-ETI-FOODSIM 2012, Food Simulation Conference, 18-20 June, 2012, Fraunhofer IVV, Freising, Germany, 91-97, 2012.

Stalder, F.: Verschiedene Korrosionsformen und -intensitäten beim Angriff von Choridlösungen auf Eisenwerkstoffe, Zürich, 1974.

Tamai, Y. and Tanaka, H.: Permeation of Small Penetrants in Hydrogel, Fluid Phase Equilibr., 144, 441-448, 1998.

Trapp, M. J. and Millero, J. F.: The Oxidation of Iron(II) with Oxygen in $\mathrm{NaCl}$ Brines, J. Solution Chem., 36, 1479-1493, 2007.

Tse, C. F. and Sandall, C. O.: Diffusion Coefficients for Oxygen and Carbon Dioxide in Water at $25^{\circ} \mathrm{C}$ by Unsteady State Desorption from a Quiescent Liquid, Chem. Eng. Commun., 3, 147-153, 1979.

Wanner, G. T.: $\mathrm{O}_{2}$-zehrende und -anzeigende Packstoffe für Lebensmittelverpackungen, PhD Thesis, TU München, 2010.

Zhang, Z.-W., Satoh, M., and Komiyama, J.: Permeability to $\mathrm{O}_{2}$ and $\mathrm{N}_{2}$ of Poly (vinyl alcohol) Membranes Swollen with Aqueous Solutions of Nonvolatile Substances, J. Membrane Sci., 31, 147-156, 1987.

Zoller, P. and Walsh, D. J.: Standard pressure-volume-temperature data for polymers, Technomic Pub. Co., Lancaster, PA, 1995. 